Original Research Paper

\title{
Application of ZnO Nano Rods for the Batch Adsorption of Cr(VI): A Study of Kinetics and Isotherms
}

\author{
Sushma Kamath, Venu Gopal Vishwakarma Ramanjaneyalu and Susmita Kamila \\ Department of Chemistry, East Point College of Engineering and Technology, Bangalore - 560 049, India
}

Article history

Received: 22-12-2018

Revised: 15-02-2019

Accepted: 11-04-2019

Corresponding Author:

Susmita Kamila

Department of Chemistry, East

Point College of Engineering

and Technology, Bangalore -

560049 , India

Bhubaneswar, Odisha.

Email: sushkam@yahoo.co.in

\begin{abstract}
The present study reports the synthesis of nano Zinc Oxide ( $\mathrm{ZnO})$ and its adsorption behaviour. The $\mathrm{ZnO}$ obtained by precipitation method were found to be well-defined nano rods arranged like flower. The shape, size and structure of $\mathrm{ZnO}$ were characterized from X-Ray Diffraction (XRD), Energy Dispersive X-ray (EDX) and Scanning Electron Microscope (SEM) analysis. These nano rods were utilized for the adsorption of hexavalent chromium ions $[\mathrm{Cr}(\mathrm{VI})]$ from their aqueous solution by using batch adsorption technique. Different physico-chemical parameters such as metal ion concentration, $\mathrm{pH}$, dosage level and equilibrium contact time were studied during adsorption. The amount of chromium adsorption increases with increase in adsorbent dosage, whereas the adsorption was maximum in the first $40 \mathrm{~min}$ with optimum value of $\mathrm{pH} 3$. The kinetic of adsorption was best fitted by the pseudo-second-order rate equation. Similarly, the equilibrium adsorption data were fitted well by both Temkin and Freundlich adsorption isotherm models in comparison to Langmuir adsorption model. The adsorption of chromium was supported by EDX and SEM analysis. Moreover, the change in the SEM morphology of $\mathrm{ZnO}$ nano rods into nano sheets after adsorption is an interesting observation of the present investigation.
\end{abstract}

Keywords: Nano Rods, Nano Sheets, Adsorbent, Hexavalent Chromium Ions, Adsorption Isotherm, Pseudo-Second-Order Kinetics

\section{Introduction}

Rapid urbanization as well as industrialization adversely affects the environment by polluting both the atmosphere and the aquatic systems. Different industries require different types of materials for their operation and the heavy metals are found to be the most essential commodities. Industries such as mining, pharmaceuticals, tanneries, electro-plating, chemical-manufacturing units etc., generates huge amount of wastes and effluents. Again the inadequately treated effluents consist of various toxic metals such as chromium, cadmium, arsenic, nickel, lead, mercury, copper etc,. The toxicities of these metals were well documented by different researchers (Förstner and Wittmann, 1985; Mukherjee, 1986; Nriago, 1988). Most of these metals were reported to be accumulated into the living tissues (Madoni et al., 1996; Oehme, 1979; Carson et al., 1986). Not only for human beings, these metals also affect in the growth of plants and animals too.

The present study is based on the separation of chromium metal from aqueous solutions. The major sources of chromium metal into the natural water systems are from tanneries, textile dyeing, metal finishing, pharmaceutics and electroplating industries. Both hexavalent and trivalent chromium are stable and exist in aqueous systems. However, hexavalent chromium is more toxic and known to be carcinogenic and mutagenic to living organisms.

There are various techniques such as ion exchange, membrane filtration, electro-chemical technologies, chemical precipitations, adsorption etc, for the effective removal of heavy metals from water (O'Connell et al., 2008; Wang et al., 2003; Sahu et al., 2009; Hashim et al., 2011). Amongst all, adsorption technique is the most preferred one due to its flexibility in designing and operation. Similarly, different types of materials were reported as effective adsorbents (Chu, 2002; Sharma and Forster, 1996; Yabe and de Oliveira, 2003; Tewari and Vivekananda, 2013). However, in the present scenario, nano based adsorbents are more convenient for the adsorption of heavy metal from aqueous solutions (Zhang and Fang, 2010; Hua et al., 2012; Mahdavi et al., 2017; Taman et al., 2015). These smart materials can separate the metals due to their increased surface to 
volume ratio. Nano metal oxides such as of titanium, iron, magnesium, aluminium, copper, zinc etc, were used by many researchers for the removal of toxic metals (Recillas et al., 2011; Agrawal and Sahu, 2006; Mahdavi et al., 2012; Sheela et al., 2012). Beside these, certain doped nano and micro-based metal adsorbents were also studied for the separation of different metals (Shenashen et al., 2017; Zolfaghari et al., 203). These materials are promising adsorbents for their high selectivity and activities towards the target components (Henglein, 1989; El-Sayed, 2001). Metal oxides along with carbon based nano adsorbents show efficiency due to their increased surface area and optimal magnetic properties (Aillon et al., 2009). Certain low cost mesoporous adsorbents (Warkocki et al., 2015; ElSafty and Shenashen, 2013), along with sensor-based adsorbents were also reported for the adsorption of various toxic metals (El-Safty et al., 2013; 2012). Review of literature showed that $\mathrm{ZnO}$ nano particles are effective for the removal of hazardous metals and contaminants from waste water (Gupta et al., 2015; Wang et al., 2010; Alswata et al., 2017; Hosseini et al., 2016). Moreover, this oxide is an eco-friendly, economical and easily synthesized nano adsorbent to be employed as an adsorbent. Apart from toxic metals, these adsorbents were also found to remove various dye-based contaminants from wastes (Zafar et al., 2018; Dehghani and Mahdavi, 2015; Konicki et al., 2018). In addition to these, certain nano $\mathrm{ZnO}$ doped with other metals have also been reported as adsorbents (Ghiloufi et al., 2016; Meng et al., 2015). Similarly, investigations involving $\mathrm{ZnO}$ nano rods were also carried out for the removal of toxic metals (Ghaedi et al., 2015; Yuvaraja et al., 2018). But, however, study related to $\mathrm{ZnO}$ with similar morphology as in the present study for chromium adsorption is found to be scarce in literature. Moreover, $\mathrm{ZnO}$ nano rods in flower arrangement are also a rare phenomenon to study. The objective of the present investigation involved with such $\mathrm{ZnO}$ nano rods with sufficient porosity for the adsorption of $\mathrm{Cr}(\mathrm{VI})$ from its aqueous solutions. As an extension work of our previous studies with the synthesis of $\mathrm{ZnO}$ nano particles by various methods (VenuGopal and Kamila, 2017), here we report the utilization of the nano $\mathrm{ZnO}$ obtained from only one synthesis method for its uniqueness.

\section{Materials and Methods}

Analytical grade zinc sulphate, sodium hydroxide, potassium dichromate were used in the experiment and were of AR grade with more than $99 \%$ purity. Concentrated nitric acid is obtained from Merck India. The chemicals were used as received without any further purification. Deionized double distilled water was used throughout the experiment.

\section{Synthesis of ZnO Nano Particles}

Zinc oxide nano particles were synthesized by precipitation method using zinc sulphate and sodium hydroxide (VenuGopal and Kamila, 2017). To the aqueous solutions of zinc sulphate $(0.1 \mathrm{M}), 0.2 \mathrm{M}$ sodium hydroxide solution was added drop wise with constant stirring till the $\mathrm{pH}$ becomes 11 . This stirring was then continued for around seven hours to get a white colour dense precipitation. The precipitates were centrifuged and dried at $100^{\circ} \mathrm{C}$ for $4 \mathrm{~h}$. These samples were kept for overnight to dry and then it is ground to make fine powders of zinc oxide. This was then characterized for the shape, size and arrangement from XRD, EDX and SEM analysis. The X-ray diffraction spectra were taken by RIGAKU smart lab X-ray Diffractometer using $\mathrm{CuK} \alpha$ radiation $\lambda=1.5405 \AA$ and $\mathrm{X}$-rays generator operating at $40 \mathrm{kv}$. The scanning range was maintained within 20-100 deg with the scanning speed of $5^{\circ} \mathrm{min}^{-1}$. The elemental composition, shape and structures of the particles have been carried out from EDX and SEM analysis by using GEMINI ULTRA 55 instruments.

\section{Batch Adsorption Studies}

A synthetic stock solution of hexavalent chromium $(1000 \mathrm{mg} / \mathrm{L})$ was prepared from potassium dichromate by dissolving $2.829 \mathrm{mg}$ in $1 \mathrm{~L}$ deionized water (Mekonnen et al., 2015; Bhattacharya et al., 2006). From this stock solution, required concentrations of chromium solutions were prepared for adsorption study.

In the batch adsorption process, the metal ions were added to the calculated amount of adsorbents in 250 $\mathrm{mL}$ Erlenmeyer flasks and were shaken under constant condition using rotary shaker to allow sufficient time for reaching adsorption equilibrium. The $\mathrm{pH}$ of the solution was adjusted by using $0.01 \mathrm{M} \mathrm{HNO}_{3}$ and 0.01 $\mathrm{M} \mathrm{NaOH}$ solutions. The initial metal ion concentration $\left(\mathrm{C}_{0}\right)$ has been varied in the range $100-500 \mathrm{mg} / \mathrm{L}$ with $\mathrm{pH} 3$ and $0.05 \mathrm{~g}$ adsorbent dose. The shaking time was for $60 \mathrm{~min}$ at $30^{\circ} \mathrm{C}$. The effect of initial $\mathrm{pH}$ on adsorption was studied in the range of 2.5-4.5 keeping the chromium ion concentration as $100 \mathrm{mg} / \mathrm{L}$ and adsorbent dose as $0.05 \mathrm{~g}$ at $30^{\circ} \mathrm{C}$ for $60 \mathrm{~min}$ shaking. Similarly, the effect of contact time $(30,40,50,60,70$ $\mathrm{min}$ ) has been carried out for $100 \mathrm{mg} / \mathrm{L}$ chromium with $0.05 \mathrm{~g}$ of adsorbent at $\mathrm{pH} 3$. Besides, the variation of adsorbent dosage has also been carried out in the range 0.02-0.1 g keeping the chromium concentration as 100 $\mathrm{mg} / \mathrm{L}$ with $60 \mathrm{~min}$ shaking at $30^{\circ} \mathrm{C}$.

After adsorption, the solution contents were centrifuged and the supernatant liquid was taken for absorption study from UV-visible spectrophotometer (ELICO made SL-159 UV-visible spectrophotometer) 
using Di-Phenyl Carbazide complex technique (DPC). The adsorbents were separated by using Whatman 41 filter paper [CAT No 1441-070]. These spent adsorbents were used for SEM, EDX analysis to know the morphology and elements. Similarly, Fourier Transform Infrared Analysis (FTIR) of $\mathrm{ZnO}$ nano particles has been done for both before and after adsorption. This analysis determines the vibrational frequency changes of the functional groups in the adsorbent.

The amounts of adsorption $\left[q_{e}(\mathrm{mg} / \mathrm{g})\right]$ at equilibrium and adsorption efficiency or percentage of removal (\%) were calculated by using the following expressions (Alswata et al., 2017):

$$
\begin{aligned}
& q_{e}(m g / g)=\frac{\left(C_{o}-C_{e}\right) V}{m} \\
& \%=\frac{C_{o}-C_{e}}{C_{o}} \times 100
\end{aligned}
$$

where, $C_{o}$ is the initial metal ion concentration and $C_{e}$ is the final metal ion concentration, $q_{e}$ is the amount of adsorbate adsorbed on the surface of the adsorbent, $V$ is the volume of solution (L), $m$ is the mass of adsorbent (g) (Oliveria et al., 2005). This removal percentage and amount of adsorption were investigated for different parameters such as metal ion concentration, effect of $\mathrm{pH}$, adsorbent amount and mixing time. Besides, the experimental data obtained were fitted into different adsorption isotherm models such as Langmuir, Freundlich and Temkin isotherm models in order to determine the sorption performance and capacity of the adsorbent.

\section{Results and Discussion}

\section{Characterization of Nano Particles}

The XRD pattern of zinc oxide nanoparticles shows (Fig. 1) well defined peaks located at Bragg angles, $(2 \theta)=$ $31.75,34.35$ and 36.23. All these characteristic peaks are in high intensity corresponding to planes having miller indices (100), (002) and (101). These peaks indicate that the products obtained are pure and good in crystalline nature. Besides, these data also provide the information about the formation of hexagonal wurtzite structure for $\mathrm{ZnO}$ nanoparticles [Ref:JCPDS file no. 36-1451]. The average crystallite size, D was calculated by using DebyeScherrer equation as below (He et al., 2008):

$$
D=\frac{K \lambda}{\beta \cos \theta}
$$

where, $K$ is Scherrer constant and the crystallite shape factor, $\lambda$ represents the wavelength of X-ray source $1.5405 \AA$ used in XRD, $\beta$ is full width at half maximum of diffraction peak and $\theta$ is the Bragg angle of intense peak. The calculated average crystallite size was found to be $37 \mathrm{~nm}$. Similarly, EDX analysis gives details of elemental composition of zinc and oxygen. The SEM morphology provides (Fig. 2) well-defined rod shaped structures of $\mathrm{ZnO}$ nanoparticles in the range of $49-140 \mathrm{~nm}$. The surface morphology plays an important role of an adsorbent for its capacity to adsorb. This depends on the surface structure of the adsorbent. In the present study the structure of nano particles obtained were of well-defined nano rods arranged in flower type. It has been observed that after adsorption, there is a significant change of the surface in presence of $\mathrm{Cr}(\mathrm{VI})$. Besides, there is increase in particle size from nano to micro after adsorption $(1.49 \mu \mathrm{m})$. The presence of chromium is supported by EDX analysis (Fig. 3 and Table 1).

The FTIR for $\mathrm{ZnO}$ nano powder as well as with chromium after adsorption have been carried out in the range $400-4000 \mathrm{~cm}^{-1}$ (using $\mathrm{KBr}$ pellet method with 0.4 $\mathrm{cm}^{-1}$ resolution in Perkin Elmer make instrument). This technique is a direct method for the identification of functional groups on the surface of the adsorbent where the adsorption depends on the porosity and the surface area of the adsorbent. The FTIR spectra of $\mathrm{ZnO}$ show several significant adsorption peaks (Fig. 4). Before adsorption, the vibration band at $485 \mathrm{~cm}^{-1}$ was related to ZnO (Zaka et al., 2011; Hong et al., 2009). Similarly the band shown at $1508 \mathrm{~cm}^{-1}$ was assigned to be of $\mathrm{O}-\mathrm{H}$ bending vibrations and this has been shifted to 1514 $\mathrm{cm}^{-1}$ after adsorption. As per the literature, hydroxyl groups were identified by the characteristic broad peak in the range $3750-3250 \mathrm{~cm}^{-1}$. This is due to the stretching vibrations of $\mathrm{OH}$ bonds (Jamhour et al., 2016). Presently, the same has been observed at $3357 \mathrm{~cm}^{-1}$ before adsorption and there is shifting of peak

\begin{tabular}{|c|c|c|c|c|c|c|c|c|c|}
\hline \multirow[b]{2}{*}{ SL No. } & \multirow[b]{2}{*}{$\mathrm{ZnO}$} & \multicolumn{2}{|l|}{$\mathrm{C}$} & \multicolumn{2}{|l|}{$\mathrm{O}$} & \multicolumn{2}{|l|}{$\mathrm{Zn}$} & \multicolumn{2}{|l|}{$\mathrm{Cr}$} \\
\hline & & $\mathrm{Wt} \%$ & At $\%$ & $\mathrm{Wt} \%$ & $\mathrm{At} \%$ & Wt $\%$ & $\mathrm{At} \%$ & Wt $\%$ & $\mathrm{At} \%$ \\
\hline 1 & Nano particles before adsorption & 18.85 & 46.65 & 11.87 & 22.01 & 69.28 & 31.43 & ---- & ---- \\
\hline 2 & Nano particles after adsorption & 11.50 & 24.68 & 32.77 & 52.82 & 50.07 & 19.99 & 5.07 & 2.51 \\
\hline
\end{tabular}
$\left(3337 \mathrm{~cm}^{-1}\right)$ for $\mathrm{ZnO}-\mathrm{Cr}$ after adsorption.

Table 1: Elemental compositions of zinc oxide nano particles before and after adsorption 


\section{Adsorption Mechanisms}

\section{Effect of Metal Ion Concentration}

The initial metal ion concentration $\left(\mathrm{C}_{0}\right)$ was varied in the range between $100-500(\mathrm{mg} / \mathrm{L})$ at $\mathrm{pH} 3$ and at $30^{\circ} \mathrm{C}$ using $0.05 \mathrm{~g}$ adsorbent. There was decrease in metal removal with increase in initial metal ion concentration. It may be due to limited number of active sites of the adsorbent that become saturated with increasing metal concentration (Alswata et al., 2017).

\section{Effect of $p H$}

The $\mathrm{pH}$ of the system controls the adsorption capacity, because this influences the surface properties of the adsorbent and ionic forms of the chromium metal in solution. Presently, the initial $\mathrm{pH}$ on adsorption was studied in the range 2.5-4.5 keeping the initial chromium ion concentration as $100 \mathrm{mg} / \mathrm{L}$ and adsorbent dose as 0.05 $\mathrm{g}$ at temperature $30^{\circ} \mathrm{C}$. The optimal $\mathrm{pH}$ for chromium removal is found to be 3 . At higher $\mathrm{pH}$ the separation is less probably due to formation of metal hydroxide. Similarly at low $\mathrm{pH}$, the metal binding sites become positively charged due to $\mathrm{H}^{+}$ions concentration and thus there is repulsion effect towards chromium ions (Singanan, 2011). Alswata et al. (2011) reported the similar observation for the removal of metal ions at acidic range. It is because of the $\mathrm{H}^{+}$ions in the solution that compete with metal ions for acidic sites on the adsorbents surface (Mahdavi et al., 2012). Similarly, according to Attia et al. (2010), the adsorption of chromium was maximum at less $\mathrm{pH}$ whereas it decreases at higher $\mathrm{pH}$.

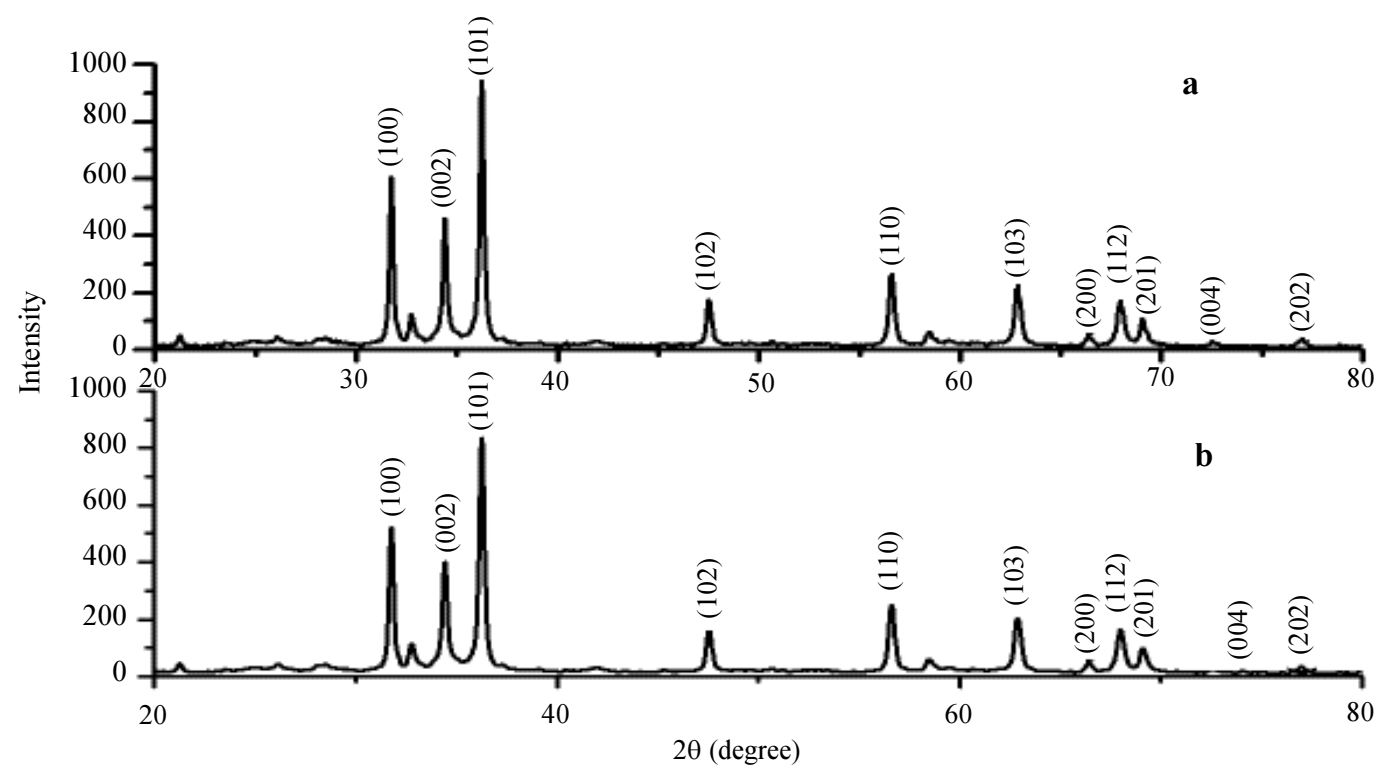

Fig. 1: X-Ray diffractogram of ZnO nano particles: (a) Sample XRD pattern and (b) standard XRD pattern
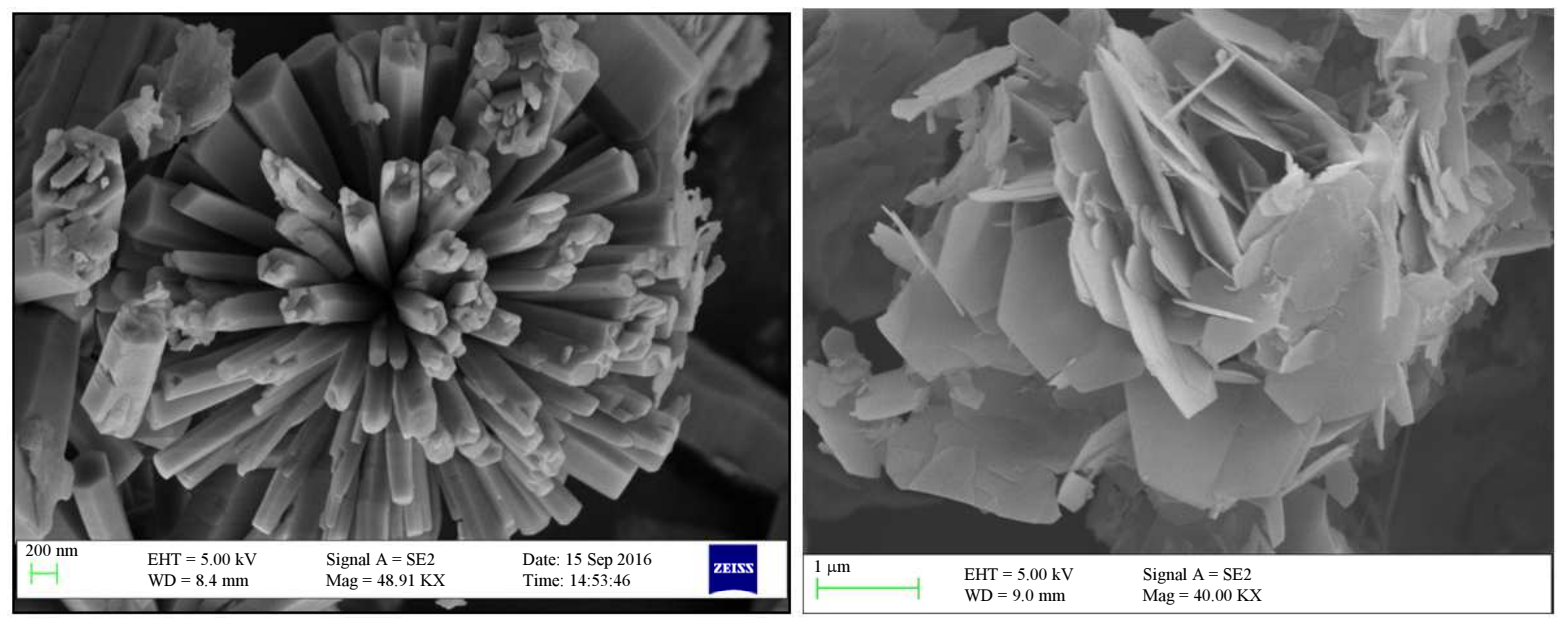

Fig. 2: (A) SEM morphology of ZnO Nano particles before adsorption (B) SEM morphology of ZnO Nano particles after adsorption 

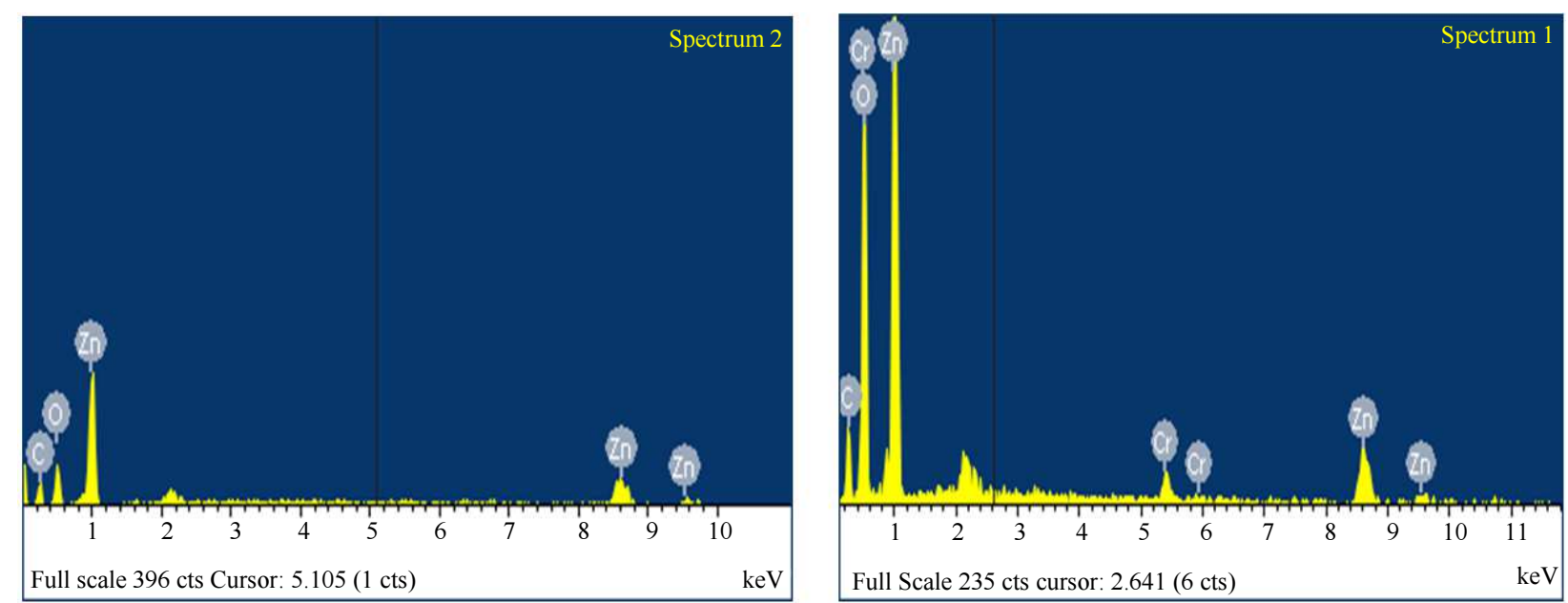

Fig. 3: (A) EDXA image of ZnO Nano particles before adsorption (B): EDXA image of ZnO Nano particles after adsorption

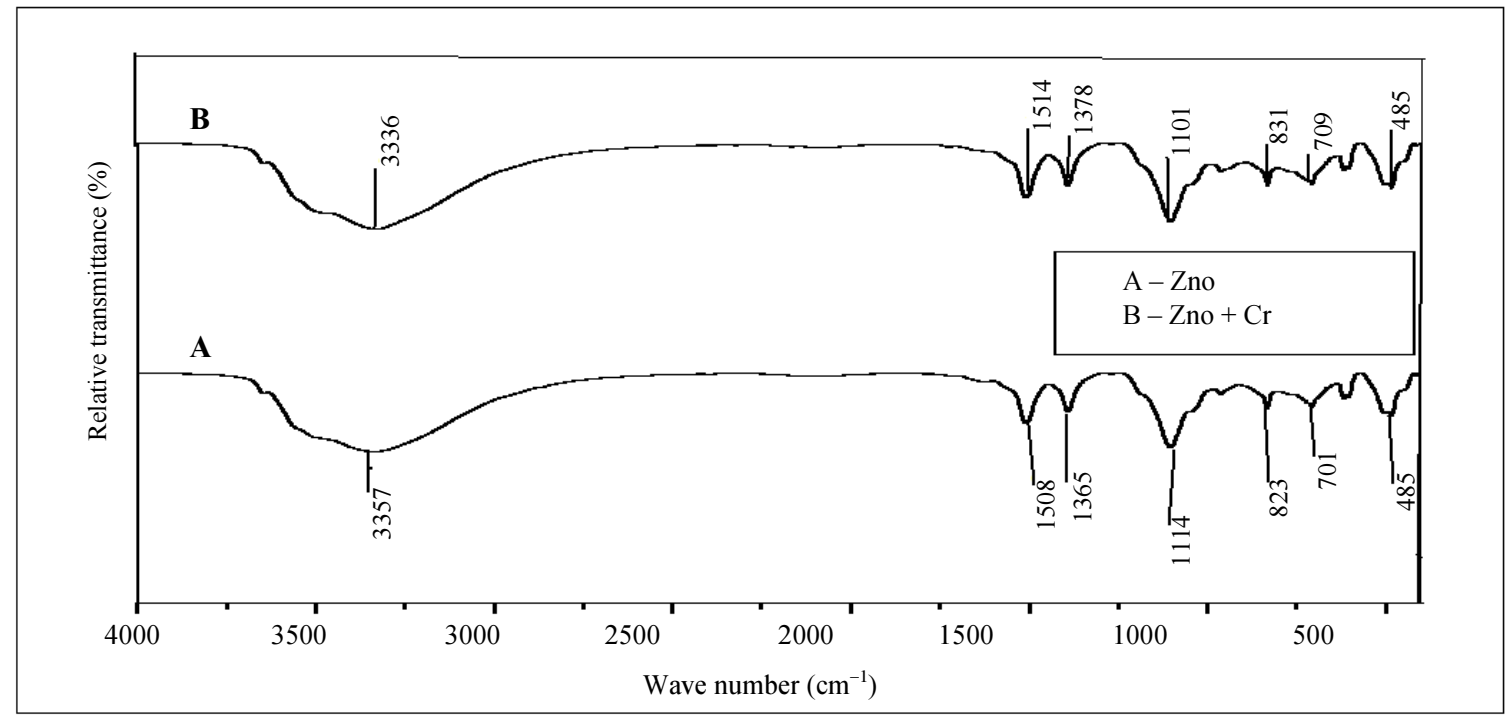

Fig. 4: FTIR of ZnO Nano particles and $\mathrm{Cr}(\mathrm{VI})$ ions adsorbed with $\mathrm{ZnO}$ Nano particles

\section{Effect of Mixing Time}

Contact time is an important factor in batch adsorption process. The extent of chromium removal was found to be increased first up to $40 \mathrm{~min}$. of mixing and then the adsorption decreases. Initially the vacant surface sites are available for adsorption but they become saturated with the metal adsorption with the time. More over it would be difficult to be occupied due to repulsive forces between the bulk phases and the solute molecules on the solid (Alswata et al., 2017; Kumar et al., 2011; Alothman et al., 2013).

\section{Effect of Adsorbent Doses}

The effect of adsorbent dosage on the adsorption was studied in the range $0.02-0.1 \mathrm{~g}$. It has been found that the removal of $\mathrm{Cr}(\mathrm{VI})$ increases with the increase in adsorbent dosage. This increment might be due to the larger surface area and availability of more adsorption sites, whereas the adsorption amount decreases with the adsorbent. This is because of the adsorptive capacity of adsorbent available was not fully utilized at a higher adsorbent dosage in comparison to lower adsorbent dosage. The percentage of removal of $\mathrm{Cr}(\mathrm{VI})$ with respect to all parameters and adsorption at equilibrium, $q_{e}$ are presented in Fig. 5 and 6, respectively.

\section{Adsorption Isotherm Models}

Adsorption isotherms are important to describe the adsorption behaviour of solute on the specific adsorbents. The equilibrium of adsorption is one of 
the physico-chemical aspects that is used for the evaluation of adsorption process as a unit operation. These models help in studying the nature of the adsorbent, surface area of the adsorbent, adsorbateadsorbent interactions and moreover the adsorption capacity of the adsorbent (Alswata et al., 2017). They also indicate the distribution of adsorbable solute between the liquid and solid phases at various equilibrium (Oliveria et al., 2005).

Langmuir isotherm assumes monolayer adsorption onto a surface containing a finite number of adsorption sites of uniform strategies without transmigration of adsorbate in the plane surface (Hameed et al., 2007). Once a site is filled, no further adsorption can take place at that site. This is indicative of the saturation point or the achievement of maximum adsorption by the surface. The linear form of this isotherm is presented as (Okoli and Ezuma, 2014; Anah and Astrini, 2018; Langmuir, 1918):

$$
\frac{1}{q_{e}}=\frac{1}{q_{m}}+\frac{1}{q_{m} K_{L} C_{e}}
$$

where, $q_{e}$ is amount of metal adsorbed $(\mathrm{mg} / \mathrm{g}) C_{e}$ is concentration after adsorption $(\mathrm{mg} / \mathrm{L}), \mathrm{q}_{m}$ is maximum monolayer coverage capacity $(\mathrm{mg} / \mathrm{g}), K_{L}$ is Langmuir constant $(\mathrm{L} / \mathrm{mg})$. A linear plot of $\left(1 / q_{e}\right)$ against $\left(1 / C_{e}\right)$ with slope $\left(1 / K_{L} q_{m}\right)$ and intercept of $\left(1 / q_{m}\right)$ shows the satisfaction of the Langmuir model for adsorption. The constants $K_{L}$ and $q_{m}$ relate to the energy of adsorption and maximum adsorption capacity, respectively.

The Freundlich model is based on the adsorption behaviour of a heterogeneous surface in multilayer coverage. It is considered to be the most popular adsorption model for a single solute system of monolayer adsorption (Freundlich, 1928). As per Freundlich model the degree of site occupation increases with the decrease in the binding strength. So the stronger binding sites are occupied first followed by the weaker binding sites. The linear form of Freundlich isotherm model is given as (Freundlich, 1907):

$\log q_{e}=\log K_{f}+\frac{1}{n} \log C_{e}$

where, $K_{f}$ is the Freundlich constant and the indicator of adsorption capacity whereas $\frac{1}{n}$ is the strength of adsorption process or adsorption intensity. These constants were determined from the slope and intercept from the plot of $\log q_{e}(\mathrm{mg} / \mathrm{g})$ against $\log C_{e}(\mathrm{mg} / \mathrm{L})$.
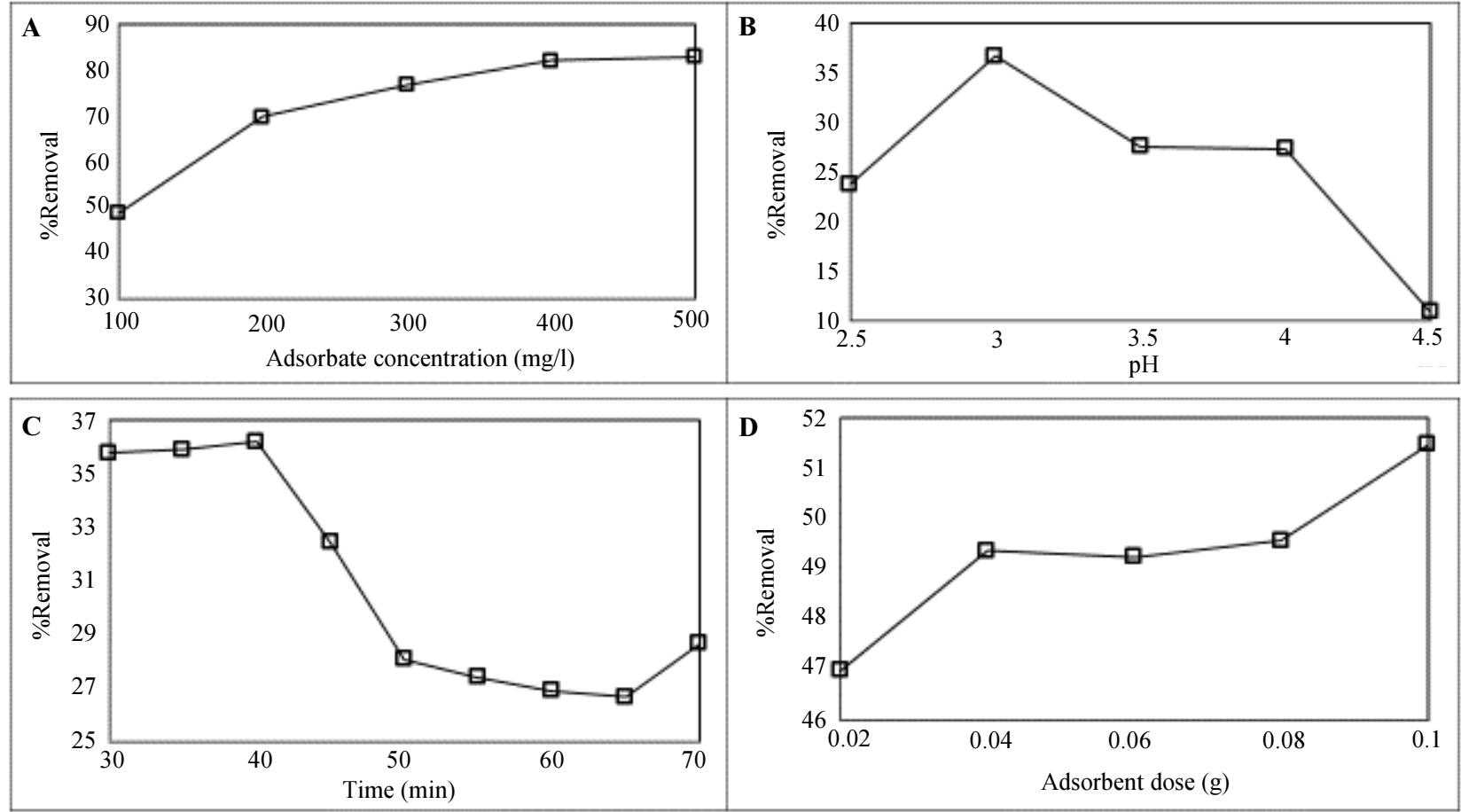

Fig. 5: (A) Effect of adsorbate concentration (mg/l) on adsorption of $\mathrm{Cr}(\mathrm{VI})$ ion. (B) Effect of $\mathrm{P}^{\mathrm{H}}$ on adsorption of $\mathrm{Cr}(\mathrm{VI})$ ion. (C) Effect of contact time (min) on adsorption of $\mathrm{Cr}(\mathrm{VI})$ ion. (D) Effect of adsorbent dose (g) on adsorption of $\mathrm{Cr}(\mathrm{VI})$ ion 


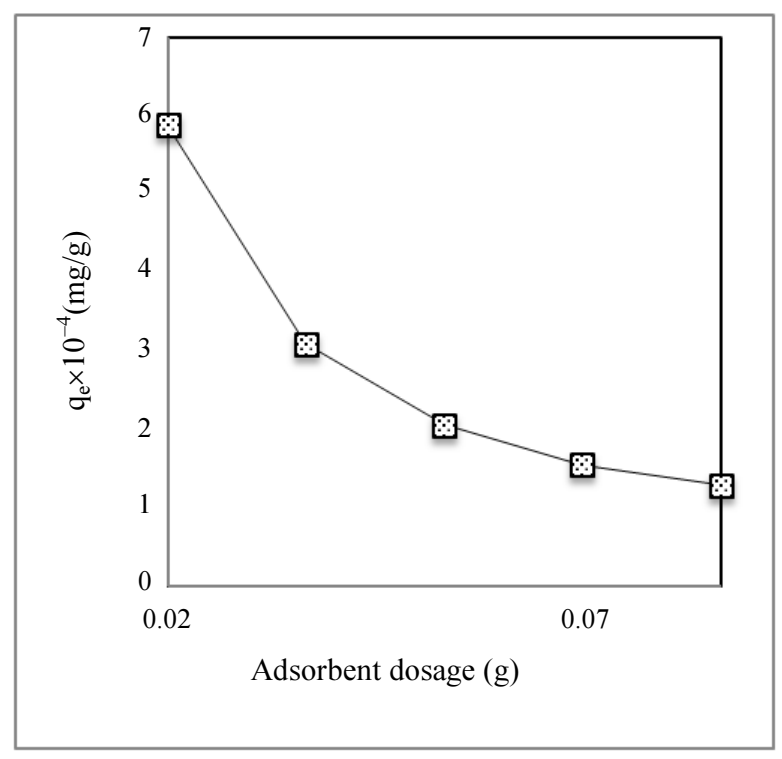

Fig. 6: Effect of adsorbent dose (g) on adsorption capacity of $\mathrm{ZnO}$ NPs

Similarly, Temkin isotherm model is based on the heat of adsorption of adsorbate molecules, which would decrease linearly with the increase in coverage of the adsorbent surface due to adsorbate-adsorbent interactions. This isotherm is used for heterogeneous surface energy systems (Mohamed et al., 2008; Atar et al., 2012) and the linear form of this isotherm model is given as (Temkin and Pyzhev, 1940; Akpomie et al., 2015):

$q_{e}=B \ln A+B \ln C e$

where, $B=R T / b, b$ is the Tempkin constant related to heat of sorption $(\mathrm{J} / \mathrm{mol}), A$ is the Temkin isotherm constant $(\mathrm{L} / \mathrm{g}), R$ is the gas constant $(8.314 \mathrm{~J} / \mathrm{mol} \mathrm{K})$ and $T$ is the absolute temperature $(\mathrm{K})$. The constants $\mathrm{A}$ and $\mathrm{B}$ are calculated from the intercept and slope of the linear plot of $q_{e}(\mathrm{mg} / \mathrm{g})$ against $\ln C_{e}$. All the isotherms are shown in Fig. 7 and the constants are presented in Table 2.

The applicability of each model is determined by comparing the correlation coefficient, $\mathrm{R}^{2}$. The higher the value of $\mathrm{R}^{2}$, the better is the goodness of the fit (Adeogun et al., 2012). In the present study, $\mathrm{R}^{2}$ values of Temkin and Freundlich isotherm models are found to be more than that of Langmuir isotherm model. Furthermore, one of the adsorption constants for Langmuir isotherm is negative, which indicates the unsuitability of this isotherm for the present study. This also reveals that heterogeneous adsorption is the preferred technique than homogeneous adsorption. The value ' $n$ ' from the Freundlich model indicates the degree of non-linearity between solution concentration and adsorption. According to literature, when $\mathrm{n}=1$, the adsorption is supposed to be of linear type and if it is more than 1, the adsorption is considered to be a physical process whereas it becomes chemical process when the value is less than 1 (Alswata et al., 2017).

\section{Kinetics of Adsorption}

Kinetics of adsorption is one of the most important characteristics that is responsible for the efficiency of adsorbents. The adsorbate can be transferred from the solution phase to the surface of the adsorbent in several steps. In order to study the mechanism of the process and potential rate controlling steps, the kinetics of adsorption onto adsorbent were analyzed by using different kinetic models. For such analysis, two kinetic models were applied in the present investigation. The kinetics of chromium adsorption on $\mathrm{ZnO}$ nano particles were analyzed by fitting the data into the Lagergrens first order model and pseudo second order equation to know the correlation coefficients $\left(\mathrm{R}^{2}\right)$. Pseudo-first order kinetics that generally describes the initial stage of the adsorption process is given as Equation 7 (Lagergren, 1898). Similarly, the pseudo-second order kinetics, which provides better description of the whole adsorption process and based on the adsorption capacity, is expressed as Equation 8 (Ho and McKay, 1999; Anbia and Parvin, 2011):

$\log \left(q_{e}-q_{t}\right)=\log q_{e}-\frac{k_{1}}{2.303} t$

$$
\frac{t}{q_{t}}=\frac{1}{k_{2} q_{e}^{2}}+\left(\frac{1}{q_{t}}\right) t
$$

where, $q_{e}$ is the amount of $\mathrm{Cr}(\mathrm{VI})$ adsorbed $\left(\mathrm{mg}^{\mathrm{g}} \mathrm{g}^{-1}\right)$ at equilibrium time and $q_{t}$ is the amount of $\mathrm{Cr}(\mathrm{VI})$ adsorbed (mg. $\left.\mathrm{g}^{-1}\right)$ at time $\mathrm{t}(\mathrm{min}) . k_{1}$ and $k_{2}$ are the first order rate constant $\left(\mathrm{min}^{-1}\right)$ and second order rate constant $\left(\right.$ g. $\left.\mathrm{mg}^{-1} \cdot \mathrm{min}^{-1}\right)$, respectively.

For first order kinetics, the value $\mathrm{k}_{1}$ is obtained from the slope of the linear plot of $\log \left(q_{e}=q_{t}\right)$ against time where the linear plot indicates the applicability of Lagergrens model. Similarly, for second order kinetics, the values of $q_{e}$ and $k_{2}$ can be determined by the slope and intercept of the linear plot of $t / q_{t}$ against time (Fig. 8).

In the present study, for pseudo first order rate kinetics, the $q_{e}$ and the rate constant, $k_{1}$ values were found to be $18.96 \mathrm{mg} . \mathrm{g}^{-1}$ and $0.002 \mathrm{~min}^{-1}$, respectively. The regression coefficient, $\mathrm{R}^{2}$ for this model was determined as 0.694. Similarly, for pseudo second order, the $q_{e}$ and rate constant, $k_{2}$ were 21.5 
mg.g ${ }^{-1}$ and 0.004 g. $\mathrm{mg}^{-1} \cdot \mathrm{min}^{-1}$, respectively. The regression coefficient, $\mathrm{R}^{2}$ was found to be 0.999 . The plot for pseudo first order model was not linear and the $\mathrm{R}^{2}$ value is much less in comparison to that of pseudo second order kinetic model. This indicates that the pseudo second order kinetic model provided good correlation for the adsorption of chromium onto nano $\mathrm{ZnO}$ in the present study. Review of literature reveals that the second order rate kinetic is indicative of chemical adsorption involving valency forces through sharing the exchange of electrons between the adsorbent and the metal ions (Idris et al., 2013).

Table 2: Adsorption constants of Langmuir, Freundlich and Temkin isotherms for $\mathrm{Cr}$ (VI) adsorption

\begin{tabular}{|c|c|c|c|c|c|c|c|c|}
\hline \multicolumn{3}{|c|}{ Langmuir isotherm } & \multicolumn{3}{|c|}{ Freundlich isotherm } & \multicolumn{3}{|c|}{ Tempkin isotherm } \\
\hline$\underline{\mathrm{q}_{\mathrm{m}}(\mathrm{mg} / \mathrm{g})}$ & $\mathrm{K}_{\mathrm{L}}(\mathrm{L} / \mathrm{mg})$ & $\mathrm{R}^{2}$ & $1 / \mathrm{n}$ & $\mathrm{K}_{\mathrm{f}}(\mathrm{mg} / \mathrm{g})$ & $\mathrm{R}^{2}$ & $\mathrm{~b}$ & $\mathrm{~A}(\mathrm{~L} / \mathrm{mg})$ & $\mathrm{R}^{2}$ \\
\hline 0.00165 & -76.313 & 0.9381 & 5.597 & $6.824 \times 10^{\alpha 6}$ & 0.992 & 85.106 & 3.162 & 0.998 \\
\hline
\end{tabular}
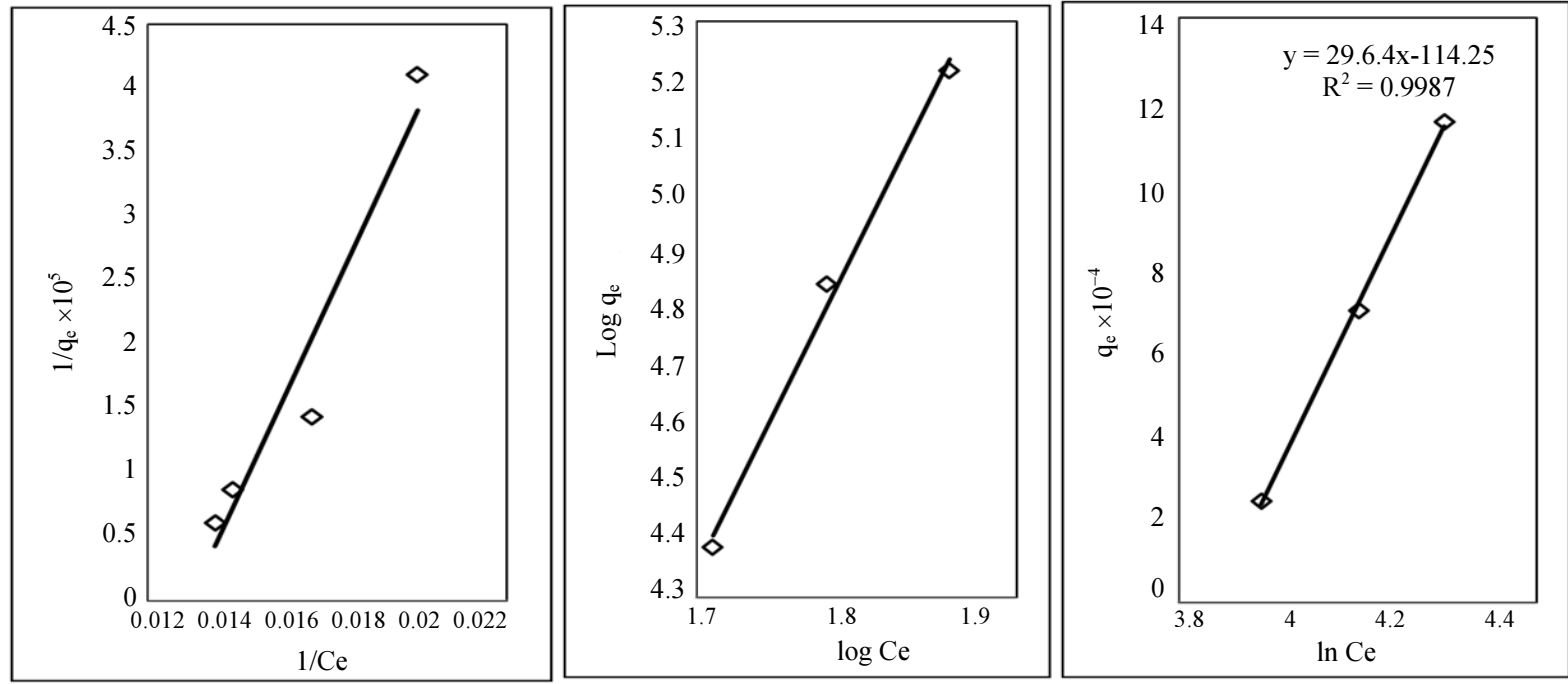

Fig. 7: (A) Langmuir adsorption isotherm for adsorption of $\mathrm{Cr}(\mathrm{VI})$ (B) Freundlich adsorption isotherm for adsorption of Cr(VI) (C) Tempkin adsorption isotherm for adsorption of $\mathrm{Cr}(\mathrm{VI})$
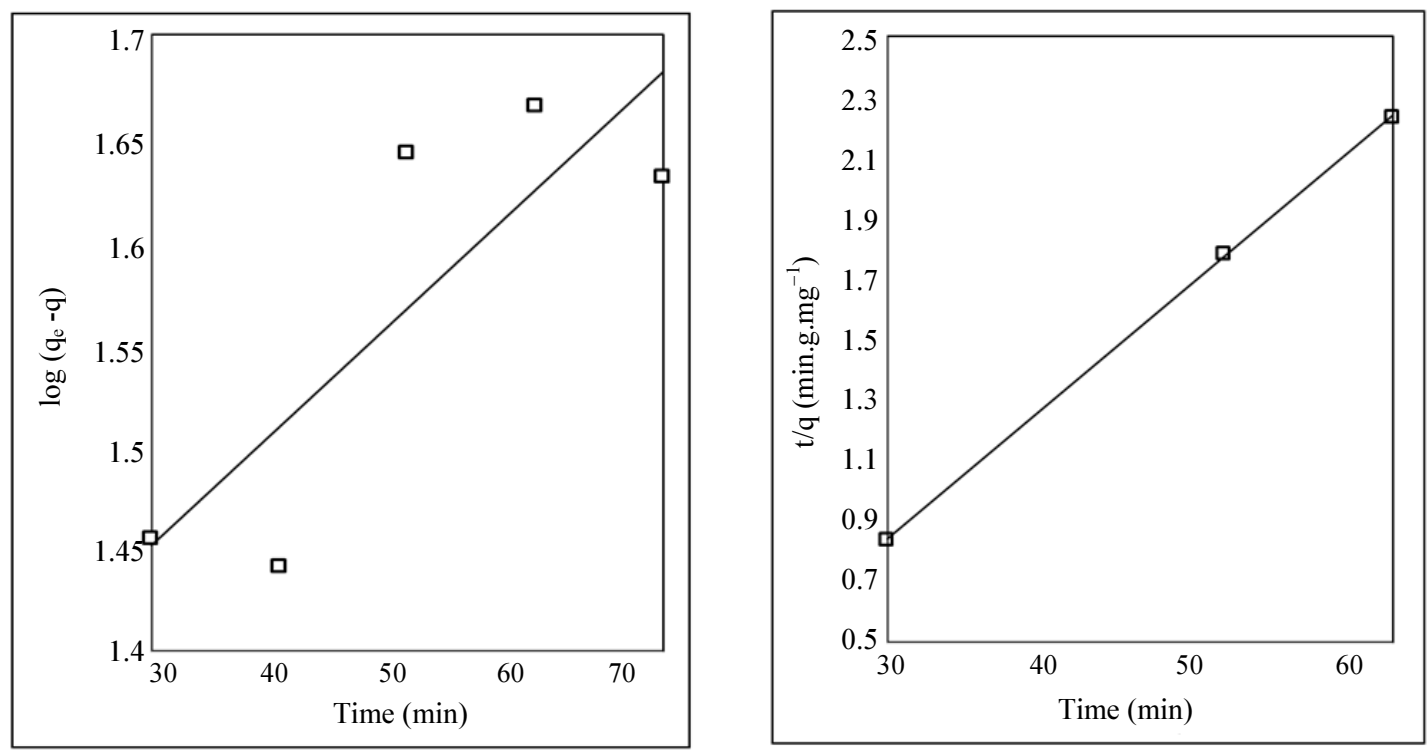

Fig. 8: (A) First order kinetics of Cr(VI) adsorption (B): Pseudo second order kinetics of Cr(VI) adsorption 


\section{Conclusion}

In this investigation, $\mathrm{ZnO}$ nano rods were prepared and characterized for their shape, size and purity successfully. The prepared nano particles were studied for the removal of $\mathrm{Cr}(\mathrm{VI})$ from aqueous solution in batch adsorption technique. The optimum parameters for the removal of $\mathrm{Cr}(\mathrm{VI})$ from $100 \mathrm{mg} / \mathrm{L}$ aqua solutions were found to be at $\mathrm{pH} 3,0.1 \mathrm{gm}$ of adsorbent dose and 40 minutes of agitation, respectively. The SEM morphology of adsorbent before and after adsorption indicates the adsorption of chromium metals over the adsorbents by changing their shape from nano rods to nano sheets. Freundlich and Temkin isotherm models have provided better fit for this metal ion to the experimental data rather than Langmuir model indicating heterogeneous adsorption as the preferred technique over homogenous adsorption. The value of $n$ in Freundlich isotherm again reveals the adsorption to be chemical rather than physical process. In addition, the adsorption kinetics shows that the mechanism followed the pseudo-second-order kinetic model indicating chemical adsorption to be the preferred one. This is an added supplement to the findings from isotherms. Moreover, the present investigation revealed that the nano rods could be used as an adsorbent for the removal of toxic metal like $\mathrm{Cr}(\mathrm{VI})$ from aqueous solutions/effluents. Furthermore, these nano materials are non-toxic, eco friendly and can easily be synthesized from very basic precursors. However, extensions of the present investigations are to be carried out further to make these nano adsorbents for actual applicability for the industrial effluents.

\section{Acknowledgement}

The authors are thankful to the R and D Centre, East Point College of Engineering and Technology, Bangalore for providing the infrastructural facilities. Visvesvaraya Technological University (VTU), Belagavi, Karnataka is gratefully acknowledged for giving the opportunity to Ms. Sushma and Mr V R Venu Gopal for their Ph.D. programme.

\section{Author's Contributions}

Sushma Kamath: Sushma is the first author and she did all the experimental work along with data collection.

Venu Gopal Vishwakarma Ramanjaneyalu: Venu Gopal's contribution includes coordination of data analysis and supporting the experimental work.

Susmita Kamila: Susmita is the supervisor and the corresponding author. Her contribution includes Research planning, organisational design and framework of the manuscript.

\section{Ethics}

No ethical issue/conflict is involved related to this work.

\section{References}

Adeogun, A.I., S.O. Kareem, J.B. Durosanya and E.S. Balogun, 2012. Kinetics and equilibrium parameters of biosorption and bioaccumulation of lead ions from aqueous solutions by Trichoderma longibrachiatum. J. Microbiol. Biotechnol. Food Sci., 1: 1221-1234.

Agrawal, A. and K.K. Sahu, 2006. Kinetic and isotherm studies of cadmium adsorption on manganese nodule residue. J. Hazardous Mater., 137: 915-924. DOI: 10.1016/j.jhazmat.2006.03.039

Aillon, K.L., Y. Xie, N. Ei-Gendy, C.J. Berkland and M.L. Forrest, 2009. Effect of nanomaterial physicochemical properties on in vivotoxicity. Adv. Drug Deliv. Rev., 61: 457-466.

DOI: 10.1016/j.addr.2009.03.010

Akpomie, K.G. F.A. Dawodu and K.O. Adebowale, 2015. Mechanism on the sorption of heavy metals from binary-solution by a low cost montmorillonite and its desorption potential. Alexandria Eng. J., 54: 757-767.

Alothman, Z.A., M. Naushad and R. Ali, 2013. Kinetic, equilibrium isotherm and thermodynamic studies of $\mathrm{Cr}(\mathrm{VI})$ adsorption onto low-cost adsorbent developed from peanut shell activated with phosphoric acid. Environ. Sci. Pollut. Res., 20: 3351-3365. DOI: 10.1007/s1 1356-012-1259-4

Alswata, A.A., M.B. Ahmad, N.M. Al-Hada, H.M. Kumari and M.Z.B. Hussain et al., 2017. Preparation of Zeolite/Zinc oxide nano composites for toxic metals removal from water. Results Phys., 7: 723-731. DOI: 10.1016/j.rinp.2017.01.036

Anah, L. and N. Astrini, 2018. Isotherm adsorption studies of $\mathrm{Ni}(\mathrm{II})$ ion removal from aqueous solutions by modified carboxymethyl cellulose hydrogel. IOP Conf. Ser.: Earth Environ. Sci., 160: 012-017. DOI: $10.1088 / 1755-1315 / 160 / 1 / 012017$

Anbia, M. and Z. Parvin, 2011. Desulfurization of fuels by means of a nanoporous carbon adsorbent. Chem. Eng. Res. Des., 89: 641-647.

DOI: 10.1016/j.cherd.2010.09.014

Atar, N., A. Olgun and S. Wangb, 2012. Adsorption of Cadmium (II) and Zinc (II) on boron enrichment process waste in aqueous solutions: Batch and fixedbed system studies. Chem. Eng. J., 192: 1-7. DOI: $10.1016 /$ j.cej.2012.03.067

Attia, A.A., S.A. Khedr and S.A. Elkholy, 2010. Adsorption of chromium ion (VI) by acid activated carbon. Braz. J. Chem. Eng., 27: 183-193. DOI: $10.1590 / \mathrm{S} 0104-66322010000100016$ 
Bhattacharya, A.K., S.N. Mandal, S.K. Das, 2006. Removal of $\mathrm{Cr}$ (VI) from aqueous solution by adsorption onto low cost non-conventional adsorbents. Ind. J. Chem. Technol., 13: 576-583.

Carson, B.L., H.V. Ellis and J.L. McCann, 1986. Toxicology and Biological Monitoring of Metals in Humans, Including Feasibility and Need. 1st Edn., Lewis Publishers, Chelsea, MI, ISBN-10: 087371072X, pp: 328.

Chu, K.H., 2002. Removal of copper from aqueous solution by chitosan in prawn shell: Adsorption equilibrium and kinetics. J. Hazardous Mater., B90: 77-95. DOI: 10.1016/S0304-3894(01)00332-6

Dehghani, M.H. and P. Mahdavi, 2015. Removal of acid 4092 dye from aqueous solution by zinc oxide nanoparticles and ultraviolet irradiation. Desalinat. Water Treatment, 54: 3464-3469.

DOI: 10.1080/19443994.2014.913267

El-Safty, S.A. and M.A. Shenashen, 2013. Optical mesosensor for capturing of $\mathrm{Fe}$ (III) and $\mathrm{Hg}$ (II) ions from water and physiological fluids. Sensors Actuators B: Chem., 183: 58-70.

DOI: $10.1016 /$ j.snb.2013.03.041

El-Safty, S.A., M.A. Shenashen and A. Shahat, 2013. Tailor-made micro-object optical sensor based on mesoporous pellets for visual monitoring and removal of toxic metal ions from aqueous media. Small, 9: 2288-2296. DOI: 10.1002/smll.201202407

El-Safty, S.A., M.A. Shenashen and A.A. Ismail, 2012. A multi-pH-dependent, single optical mesosensor/captor design for toxic metals. Chem. Commun., 48: 9652-9654. DOI: $10.1039 / \mathrm{c} 2 \mathrm{cc} 34788 \mathrm{a}$

El-Sayed, M.A., 2001. Some interesting properties of metals confined in time and nanometer space of different shapes. Acc Chem. Res., 34: 257-264. DOI: $10.1021 / \operatorname{ar} 960016 \mathrm{n}$

Förstner, U. and G.T.W. Wittmann, 1985. Metals in the Aquatic Environment. 1st Edn., Springer, New York.

Freundlich, H., 1907. Über die Adsorption in Lösungen. Zeitschrift für Physikalische Chemie - Stöchiometrie und Verwandschaftslehre, 57: 385-470.

Freundlich, H., 1928. Colloid and Cpillary Chemistry. EP Dutton and Co., New York.

Ghaedi, M., A.G. Nasab, S. Khodadoust, R. Sahrael and A. Daneshfar, 2015. Characterization of zinc oxide nanorods loaded on activated carbon as cheap and efficient adsorbent for removal of methylene blue. J. Indus. Eng. Chem., 21: 986-993. DOI: $10.1016 /$ j.jiec.2014.05.006

Ghiloufi, I., J. El-Ghoul, A. Modwi and L. El-Mir, 2016. Ga-doped $\mathrm{ZnO}$ for adsorpsion of heavy metals from aqueous solution. Mater. Sci. Semi Conductor Process., 42: 102-106.

DOI: $10.1016 /$ j.mssp.2015.08.047
Gupta, V.K., I. Tyagi, H. Sadegh, R. ShahryariGhoshekandi and A.S.H. Makhlouf et al., 2015. Nanoparticles as Adsorbent: A positive approach for removal of noxious metal ions: A review. Sci. Technol. Dev., 34: 195-214.

Hameed, B.H., A.T.M. Din and A.L. Ahmad, 2007. Adsorption of methylene blue onto bamboo-based activated carbon kinetics and equilibrium studies. J. Hazardous Mater., 141: 819-825. DOI: $10.1016 /$ j.jhazmat.2006.07.049

Hashim, M.A., S. Mukhopadhyay, J.N. Sahu and B. Sengupta, 2011. Remediation technologies for heavy metal contaminated groundwater. J. Environ. Manage., 92: 2355-2388. DOI: $10.1016 /$ j.jenvman.2011.06.009

He, C., T. Sasaki, Y. Shimizu and N. Koshizaki, 2008. Synthesis of $\mathrm{ZnO}$ nanoparticles using nanosecond pulsed laser ablation in aqueous media and their self-assembly towards spindle-like $\mathrm{ZnO}$ aggregates. Applied Surface Sci., 254: 2196-2202.

DOI: 10.1016/j.apsusc.2007.09.007

Henglein, A., 1989. Small-particle research: Physicochemical properties of extremely small colloidal metal and semiconductor particles. Chem. Rev., 89: 1861-1873. DOI: 10.1021/cr00098a010

Ho, Y.S. and G. McKay, 1999. Pseudo-second order model for sorption processes. G Process Biochem., 34: 451-465. DOI: 10.1016/S0032-9592(98)00112-5

Hong, R.Y., J.H. Li, L.L. Chen, D.Q. Liu and H.Z. Li et al., 2009. Synthesis, surface modification and photocatalytic property of $\mathrm{ZnO}$ nanoparticles. Powder Technol., 189: 426-432.

DOI: $10.1016 /$ j.powtec.2008.07.004

Hosseini, S.A., S. Mashaykhi and S. Babaei, 2016. Graphene oxide/zinc oxide nanocomposite: A superior adsorbent for removal of methylene blue statistical analysis by Response Surface Methodology (RSM). South African J. Chem., 69: 105-112. DOI: 10.17159/0379-4350/2016/v69a13

Hua, M., S. Zhang, B. Pan, W. Zhang and L. Lv et al., 2012. Heavy metal removal from water/wastewater by nanosized metal oxides: A review. J. Hazardous Mater., 211-212: 317-331.

Idris, S.A., K.M. Alotaibi, T.A. Peshkur, P. Anderson and M. Morris et al., 2013. Adsorption kinetic study: Effect of adsorbent pore size distribution on the rate of $\mathrm{Cr}$ (VI) uptake. Microporous Mesoporous Mater., 165: 99-105. DOI: 10.1016/j.micromeso.2012.08.001

Jamhour, R.M.A.Q., T.S. Ababneh, A.I. Al-Rawashdeh, G.M. Al-Mazaideh and T.M.A. Al Shboul et al., 2016. Adsorption isotherms and kinetics of $\mathrm{Ni}(\mathrm{II})$ and $\mathrm{Pb}(\mathrm{II})$ ions on new layered double hydroxidesnitrilotriacetate composite in aqueous media. Adv. Analytical Chem., 6: 17-33. 
Konicki, W., D. Sibera and U. Narkiewicz, 2018. Adsorptive removal of cationic dye from aqueous solutions by $\mathrm{ZnO} / \mathrm{ZnMn}_{2} \mathrm{O}_{4}$ nanocomposite. Separat. Sci. Tech., 53: 1295-1306. DOI: $10.1080 / 01496395.2018 .1444054$

Kumar, S., V.C. Srivastava and R. Badoni, 2011. Studies on adsorptive desulfurization by zirconia based adsorbents. Fuel, 90: 3209-3216. DOI: $10.1016 /$ j.fuel.2011.06.029

Lagergren, 1898. About the theory of so-called adsorption of soluble substances. Kungliga Svenska Vetenskapsakademiens Handlingar, 24: 1-39.

Langmuir, I., 1918. Adsorption of gases on plane surfaces of glass, mica and platinum. J. Am. Chem. Soc., 40: 1361-1403. DOI: 10.1021/ja02242a004

Madoni, P., D. Davoli, G. Gorbi and L. Vescovi, 1996. Toxic effect of heavy metals on the activated sludge protozoan community. Water Res., 30: 135-142. DOI: 10.1016/0043-1354(95)00124-4

Mahdavi, S., M. Jalali and A. Afkhami, 2012. Removal of heavy metals from aqueous solutions using $\mathrm{Fe}_{3} \mathrm{O}_{4}$, $\mathrm{ZnO}$ and $\mathrm{CuO}$ nanoparticles. J. Nanoparticle Res., 14: 846-846. DOI: 10.1007/s11051-012-0846-0

Mahdavi, S., M. Jalali and A. Afkhami, 2013. Heavy metals removal from aqueous solutions using $\mathrm{TiO}_{2}$, $\mathrm{MgO}$ and $\mathrm{Al}_{2} \mathrm{O}_{3}$ nanoparticles. Chem. Eng. Comm., 200: 448-470.

DOI: $10.1080 / 00986445.2012 .686939$

Mekonnen, E., M. Yitbarek and T.R. Soreta, 2015. Kinetic and thermodynamics studies of the adsorption of $\mathrm{Cr}(\mathrm{VI})$ onto some selected local adsorbents. S. Af. J. Chem., 68: 45-52.

Meng, A., J. Xing, Z. Ei and Q. Li, 2015. Chromium doped $\mathrm{ZnO}$ nanoparticles: Synthesis, characterization adsorption property and reclycability. ACS Applied Mater. Interfaces, 7: 27449-27457. DOI: 10.1021/acsami.5b09366

Mohamed, A., G.I. Hesham and M.A. Mohamed, 2008. Equilibrium and kinetics of chromium adsorption on cement kiln dust. Proceedings of the World Congress on Engineering and Computer Science, Oct. 22-24, San Francisco, pp: 54-62.

Mukherjee, A.G., 1986. Environmental pollution and health hazards: Causes and control. Galgotia Publication, New Delhi.

Nriago, J.O., 1988. A silent epidemic of metal poisoning. Environ. Pollut., 50: 139-161. DOI: $10.1016 / 0269-7491(88) 90189-3$

O'Connell, D.W., C. Birkinshaw and T.F. O'Dwyer, 2008. Heavy metal adsorbents pre-pared from the modification of cellulose: A review. Bioresour. Technol., 99: 6709-6724.

DOI: $10.1016 /$ j.biortech.2008.01.036

Oehme, F.W., 1979. Toxicity of Heavy Metals in the Environment. 1st Edn., Marcel Dekker, New York, ISBN-10: 0608064688, pp: 469.
Okoli, J.U. and I.B.E. Ezuma, 2014. Adsorption studies of heavy metals by low cost adsorbents. J. Applied Sci. Environ. Manage., 18: 443-448.

Oliveria, E.A., S.F. Montanher, A.D. Andrader, J.A. Nobrega and M.C. Rollemberg, 2005. Equilibrium studies for the sorption of chromium and nickel from aqueous solution using rice bran. Process Biochem., 40: 3485-3490. DOI: $10.1016 /$ j.procbio.2005.02.026

Recillas, S., A. Garcia, E. Gonzalez, E. Casals and V. Puntes et al., 2011. Use of $\mathrm{CeO}_{2}, \mathrm{TiO}_{2}$ and $\mathrm{Fe}_{3} \mathrm{O}_{4}$ nanoparticles for the removal of lead from water: Toxicity of nanoparticles and derived compounds. Desalination, 277: 213-220. DOI: 10.1016/j.desal.2011.04.036

Sahu, S.K., P. Meshrm, B.D. Pandey, V. Kumar and T.R. Mankhand, 2009. Removal of chromium(III) by cation exchange resin', Indion 790 for tannery waste treatment. Hydrometallurgy, 99: 170-174. DOI: 10.1016/j.hydromet.2009.08.002

Sharma, D.C. and C.F. Forster, 1996. Removal of hexavalent chromium from aqueous solutions by granular activated carbon. Water SA, 22: 153-160.

Sheela, T., Y.A. Nayaka, R. Viswanatha, S. Basavanna and T. Venkatesha, 2012. Kinetics and thermodynamics studies on the adsorption of $\mathrm{Zn}$ (II), $\mathrm{Cd}(\mathrm{II})$ and $\mathrm{Hg}(\mathrm{II})$ from aqueous solution using zinc oxide nanoparticles. Powder Technol., 217: 163-170. DOI: 10.1016/j.powtec.2011.10.023

Shenashen, M.A., N. Akhtar, M.M. Selim, W.M. Morsy and H. Yamaguchi et al., 2017. Effective, low $\square$ cost recovery of toxic arsenate anions from water by using hollow-sphere geode traps. Chemistry: Asian J., 12: 1952-1964. DOI: 10.1002/asia.201700666

Singanan, M., 2011. Removal of lead(II) and cadmium(II) ions from wastewater using activated biocarbon. ScienceAsia, 37: 115-119. DOI: $10.2306 /$ scienceasia1513-1874.2011.37.115

Taman, R., M.E. Ossman, M.S. Mansour and H.A. Farag, 2015. Metal oxide nano-particles as an adsorbent for removal of heavy metals. Adv. Chem. Eng., 5: 1-125.

Temkin, M.I. and V. Pyzhev, 1940. Kinetics of ammonia synthesis on protonated iron catalyst. Acta Physicochem. USSR, 12: 217-222.

Tewari, H. and Vivekananda, 2013. Removal of heavy metals from industrial effluents using Pinus roxburghii leaves as biosorbent: Equilibrium modelling. Water Sci. Technol., 67: 1894-1900. DOI: $10.2166 /$ wst.2013.034

VenuGopal, V.R. and S. Kamila, 2017. Effect of temperature on the morphology of $\mathrm{ZnO}$ nanoparticles: A comparative study. Applied Nanosci., 7: 75-82. 
Wang, X., W. Cai, Y. Lin, G. Wang and C. Liang, 2010. Mass production of micro/nano structured porous $\mathrm{ZnO}$ plates and their strong structurally enhanced and selective adsorption performance for environmental remediation. J. Mater. Chem., 20: 8582-8590. DOI: $10.1039 / \mathrm{c} 0 \mathrm{jm} 01024 \mathrm{c}$

Wang, Y.H., S.H. Lin and R.S. Juang, 2003. Removal of heavy metal ions from aqueous solutions using various low-cost adsorbents. J. Hazard. Mater., 102: 291-302. DOI: 10.1016/S0304-3894(03)00218-8

Warkocki, W., S.A. El-Safty, M.A. Shenashen, E. Elshehy and H. Yamaguchi et al., 2015. Photoinduced recovery, optical detection and separation of noxious $\mathrm{SeO}_{3}{ }^{2-}$ using a mesoporous nanotube hybrid membrane. J. Mater. Chem. A, 3: 17578-17589. DOI: $10.1039 / \mathrm{C} 5$ TA02827B

Yabe, M.J.S. and E. de Oliveira, 2003. Heavy metals removal in industrial effluents by sequential adsorbent treatment. Adv. Environ. Res., 7: 263-272. DOI: 10.1016/S1093-0191(01)00128-9

Yuvaraja, G., C. Prasad, Y. Vijaya and M.V. Subbaiah, 2018. Application of $\mathrm{ZnO}$ nanorods as an adsorbent material for the removal of As(III) from aqueous solution: Kinetics, isotherms and thermodynamic studies. Int. J. Ind. Chem., 9: 17-25.

DOI: $10.1007 / \mathrm{s} 40090-018-0136-5$
Zafar, M.N., Q. Dar, F. Nawaz, M.N. Zafar and M. Iqbal et al., 2018. Effective adsorptive removal of azo dyes over spherical $\mathrm{ZnO}$ nanoparticles. J. Mater. Res. Technol.

DOI: $10.1016 /$ j.jmrt.2018.06.002

Zaka, A.K., A.W.H. Majid, M. Darroudi and R. Yousefi, 2011. Synthesis and characterization of $\mathrm{ZnO}$ nanoparticles prepared in gelatin media. Mater. Lett., 65: 70-73.

Zhang, L. and M. Fang, 2010. Nanomaterials in pollution trace detection and environmental improvement. Nano Today, 5: 128-142.

DOI: $10.1016 / \mathrm{j}$.nantod.2010.03.002

Zolfaghari, G., A. Esmaili-Sari, M. Anbia, H. Younesi and M.B. Ghasemian, 2013. A zinc oxide-coating mesoporous carbon adsorbent for lead removal from water: Optimization, equilibrium, modelling and kineticss studies. Int. J. Environ. Sci., 10: 325-340. 